\title{
Cinacalcet in hyperparathyroidism secondary to X-linked hypophosphatemic rickets: case report and brief literature review
}

\author{
Maria P. Yauropoulou ${ }^{1}$, Kalliopi Kotsa ${ }^{1}$, Anna Gotzamani Psarrakou ${ }^{2}$, \\ Alexandra Papazisi' ${ }^{2}$, Theoni Tranga ${ }^{3}$, Stelios Ventis ${ }^{3}$, John G. Yovos ${ }^{1}$
}

${ }^{1}$ Endocrinology and Metabolism Division, ${ }^{2}$ Nuclear Medicine Department, AUTH, Thessaloniki, ${ }^{3}$ BioAnalytica-Genotype S.A. Athens, Greece

\begin{abstract}
$\mathrm{X}$-linked dominant hypophosphatemic rickets (XLH) is the most prevalent genetic form of hypophosphatemic rickets. Standard treatment of XLH patients includes long-term administration of phosphate and calcitriol. Treated patients usually respond well to the conventional therapy and demonstrate amelioration of rachitic symptoms and improved growth. However, long-term administration of phosphate and vitamin $D$ preparations is sometimes complicated with nephrocalcinosis, secondary or tertiary hyperparathyroidism and arterial hypertension. We describe a patient with XLH, caused by a rare missense mutation of the PHEX gene. The patient, while under treatment with alphacalcidol and oral phosphate, developed hypercalciuria, nephrocalcinosis, secondary hyperparathyroidism and arterial hypertension. Cinacalcet was added to the therapeutic regimen and the long-term effects on calciotropic parameters and FGF23 levels are herein reported.
\end{abstract}

Key words: Cinacalcet, Hyperparathyroidism, Hypophosphatemic rickets, PHEX gene, Vitamin D

\section{INTRODUCTION}

$\mathrm{X}$-linked dominant hypophosphatemic rickets (XLH) is the most prevalent genetic type of hypophosphatemic rickets caused by germ line mutations in the PHEX gene. Mutations are found in approxi-

Address for correspondence:

Maria P Yavropoulou, MD, Endocrinology and Metabolism Division, $1^{\text {st }}$ Internal Medicine Department, AHEPA University Hospital, 1 S. Kyriakidi street, 54636, Thessaloniki, Greece, Tel:+302310994614, Fax: +302310994608, e-mail: margia@med.auth.gr

Received 20-01-10, Revised 10-04-10, Accepted 15-05-10 mately $85 \%$ of familial cases and in about $50 \%$ of sporadic cases.

Inactive mutations of the PHEX gene, which encodes a membrane endopeptidase, result in increased levels of circulating phosphatonins, due to reduced degradation or increased production. ${ }^{1}$ Fibroblast growth factor 23 (FGF 23) is considered to be the main phosphatonin, and increased levels have been observed in XLH and in the autosomal dominant form of hypophosphatemic rickets (ADHR). ${ }^{2}$

Established treatment of XLH includes high doses of oral phosphate and calcitriol. ${ }^{3,4}$ Although 
treated patients demonstrate amelioration of rachitic symptoms and improved growth, ${ }^{5}$ long-term administration of phosphate and vitamin D preparations is sometimes complicated with nephrocalcinosis, ${ }^{6}$ secondary hyperparathyroidism, ${ }^{5}$ hypertension ${ }^{7}$ and cardiovascular abnormalities. ${ }^{8}$

Hyperparathyroidism and hypercalcemia contribute to the development of hypertension and transient renal dysfunction in XLH patients. ${ }^{9}$

Alternative ways that could provide improved control of serum PTH, calcium and vitamin D levels are of critical importance for the well-being of these patients.

Recently, the calcimimetic drug cinacalcet has been reported to exert a beneficial effect in XLH patients, lowering the calcium phosphate product and improving renal function and arterial blood pressure in patients who developed secondary hyperparathyroidism. ${ }^{9,10}$

We describe a case with XLH caused by a rare missense mutation in the PHEX gene, who, on treatment with alfacalcidol and oral phosphate, developed moderate secondary hyperparathyroidism and arterial hypertension. We administered cinacalcet to our patient for six months and we herein report the long-term effects on serum concentrations of calcium, PTH, 25-OH-vitamin- $\mathrm{D}_{3}$, FGF23, phosphate clearance and transport maximum of phosphate per glomerular filtration rate (TmP/GFR).

\section{METHODS}

The study was performed according to the 1975 Helsinki Declaration, as revised in 2000. Informed consent was obtained from the patient.

\section{Biochemical assays}

Serum and plasma samples for $25-(\mathrm{OH})$-vitamin- $\mathrm{D}_{3}$ and FGF23 measurement were immediately frozen after collection and kept at $-70^{\circ} \mathrm{C}$ until analysis. Serum 25-(OH)-vitamin- $\mathrm{D}_{3}$ levels were analyzed by commercial RIA kit (Diasorin; Minessota, USA) according to the manufacturer's instructions. Minimum detection limit is $1.5 \mathrm{ng} / \mathrm{ml}$ (confidence level $95 \%$ ). The intra- and inter-assay \% C.V is 8.6-11.7 \% and 8.2$11 \%$ respectively. Plasma FGF23 levels were analyzed by EIA kit at Mayo Medical Laboratories (USA). The assay uses 2 affinity-purified goat antibodies that bind at the carboxyl terminal portion of FGF23. One antibody is coated onto micro titer wells and the other is biotinylated. Horseradish peroxide conjugated to avidin and 3.3', 5,5'-tetramethylbenzidine (TMB) substrate provide the colored product, which is read in a micro titer plate spectrophotometer.

All other tests (serum and urine calcium, albumin, ionized calcium, serum and urine phosphorus, BUN, creatinine, intact PTH) were performed by methods used routinely in the Department of Biochemistry of the AHEPA University Hospital.

\section{Mutational analysis}

Genomic DNA was extracted from peripheral blood using the Qiamp Blood extraction kit (Qiagen, Hilden, Germany) according to the manufacturer's instructions. To test for the presence of deletions or duplications, multiplex ligation-dependent probe amplification (MLPA) analysis was applied using the SALSA MLPA KIT P223 PHEX (MRC Holland). Gene exons, including the intron-exons splice junctions, were PCR amplified with intronic primers. Amplified exons were analyzed by DNA sequencing applying Big Dye Terminator Chemistry using an ABI prism 3130 sequencer.

\section{Patient's description}

A 39 year old white woman, was diagnosed with hypophosphatemic rickets when she was 9 years old and she has been treated with oral phosphate $500 \mathrm{mg}$ (tab eff Phosphate Sandoz ${ }^{\circledR}$ ) 4 times daily and alfacalcidol (soft caps One alpha ${ }^{\circledR}$ ) $1 \mu \mathrm{g} /$ day ever since. She presented with short stature $(145 \mathrm{~cm})$ and bow legged. Her bone mineral density (BMD) measured by DEXA was within normal limits (T-score $=1,02$ ). Her mother was also reported as having hypophosphatemia and short stature but she had never been further examined. Her 9-year old daughter developed subnormal serum phosphate levels and the characteristic features of rickets at the age of 4 years. Her height was $110 \mathrm{~cm}$, below the $3^{\text {rd }}$ percentile on the appropriate growth chart and her growth rate has been less than $3 \mathrm{~cm}$ per year in the last 4 years. Her 7-year old son was also diagnosed with hypophosphatemic rickets at the age of 5 . His height was $105 \mathrm{~cm}$, below 
the $3^{\text {rd }}$ percentile on the appropriate growth chart and his growth rate has been approximately $1.5 \mathrm{~cm}$ per year in the last 2 years. Both children have been treated with oral phosphate $500 \mathrm{mg}$ (tab eff Phosphate Sandoz $\left.{ }^{\circledR}\right) 3$ times daily as well as alfacalcidol (soft caps One alpha $\left.{ }^{\circledR}\right) 1 \mu \mathrm{g} /$ day.

The index case presented to our outpatient Clinic with biochemical deterioration of hypophosphatemia, worsening of bone pain and recent onset of moderate arterial hypertension. She also reported frequent urinary tract infections and dental abscesses during the last year. The biochemical evaluation (Table 1) revealed elevated levels of parathyroid hormone, calcium levels in the upper normal limit, hypercalciuria, high levels of phosphorus clearance, low levels of serum phosphate, low transport maximum of phosphate per glomerular filtration rate (TmP/GFR) and normal concentrations of creatinine and Blood Urea Nitrogen (BUN). An ultrasonographic examination of her kidneys revealed moderate nephrocalcinosis.

Because of her personal and family history, the diagnosis of a X-linked form of hypophosphatemic rickets was suspected and a genetic analysis was performed in three affected members of the family. No deletions or duplications were detected in the PHEX gene. A rare missense mutation was revealed in exon 15, which involved a substitution of leucine for proline (CCG"CUG), at codon 534. The results were interpreted according to the sequence data published in GenBank accession number NT-011757.14. On long term treatment with alfacalcidol and oral phosphate the patient had a height of $145 \mathrm{~cm}$ and minimal bone deformities. However, the administration of phosphate led to a progressive reduction of ionized calcium and elevated PTH levels, resulting in secondary hyperparathyroidism. In addition, the patient presented increased urine calcium excretion, and development of nephrocalcinosis.

Following her evaluation in our center, we added $60 \mathrm{mg}$ of cinacalcet to the previous therapeutic regimen. The patient quickly became normotensive (from $150 / 90 \mathrm{mmHg}$ to $120 / 85 \mathrm{mmHg}$ ) and the new medication was well tolerated.

One month after initiation of cinacalcet the patient's data showed a decrease in serum calcium and an increase in serum phosphate, while PTH levels and calciuria were normalized (Table 1). Moreover, baseline FGF23 levels were markedly decreased from $108 \mathrm{RU} / \mathrm{ml}$ to $46 \mathrm{RU} / \mathrm{ml}$ following treatment with cinacalcet.

Six months after the treatment modification the

Table 1. Biochemical data before and after 1 and 6 months of cinacalcet treatment

\begin{tabular}{lccc}
\hline & \multirow{2}{*}{$\begin{array}{c}\text { Before } \\
\text { Laboratory findings (normal range) }\end{array}$} & \multicolumn{2}{c}{ Treatment with cinacalcet } \\
\cline { 3 - 4 } treatment & $\mathbf{1}$ month & $\mathbf{6}$ months \\
\hline Total serum calcium $(2.1-2.6 \mathrm{mmol} / \mathrm{L})$ & 2.35 & 2.195 & 2.16 \\
{$\left[\mathrm{Ca}^{2+}\right](1.1-1.4 \mathrm{mmol} / \mathrm{L})$} & 1.112 & 1.25 & 1.2395 \\
Serum Protein $(66-87 \mathrm{gr} / \mathrm{L})$ & 75 & 80.9 & 79.8 \\
Serum Phosphate $(1.0-1.4 \mathrm{mmol} / \mathrm{L})$ & 0.646 & 0.9367 & 1.0013 \\
Serum Creatinine $(35.4-97.4 \mu \mathrm{mol} / \mathrm{L})$ & 39.78 & 51.28 & 37.13 \\
Blood Urea Nitrogen $(3.57-17.85 \mathrm{mmol} / \mathrm{L})$ & 16.07 & 11.424 & 9.99 \\
iPTH $(1.6-6.9 \mathrm{pmol} / \mathrm{L})$ & 16 & 9.3 & 5.9 \\
25(OH)-Vitamin D $(100-250 \mathrm{nmol} / \mathrm{L})$ & 62.4 & 72.9 & 71.3 \\
FGF23 RU/ml (6.8-71.4) & 108 & 46 & 45 \\
Urine Calcium $(2.5-8.0 \mathrm{mmol} / \mathrm{L})$ & 8.7 & 7.7 & 7.0 \\
Calcium/creatinine clearance ratio & 0.8 & 0.3 & 0.35 \\
Phosphate clearance $(11 \pm 2.5 \mathrm{ml} / \mathrm{min})$ & 28.6 & Not measured & 16.63 \\
Transport maximum of phosphate per glomerular filtration rate $(\mathrm{Tm} / \mathrm{GFR})$ & 0.34 & Not measured & 0.912 \\
(0.8-1.3 mmol/liter) & & &
\end{tabular}


patient demonstrated a stable improvement of her biochemical features and clinical condition.

\section{DISCUSSION}

$\mathrm{X}$-linked dominant hypophosphatemic rickets $(\mathrm{XLH})$ is the most prevalent genetic form of hypophosphatemic rickets worldwide with an approximate prevalence of 1 in $20,000 .{ }^{11}$ The disease is characterized by short stature, bone pain, enthesopathy (calcification of tendons and ligaments) and lower extremity deformities due to progressive rickets and osteomalacia. ${ }^{11}$ Biochemical features of the disease include hypophosphatemia secondary to renal phosphate loss, as well as inappropriately normal 1,25dihydroxyvitamin- $\mathrm{D}_{3}$ concentrations. The genetic background involves inactivating mutation in PHEX gene. ${ }^{12}$ The mutation c. $1601 \mathrm{C}>\mathrm{T}$ in the PHEX gene, detected in our patient was previously described in two unrelated French families ${ }^{13}$ and in a few other cases $^{14-16}$ with similar clinical phenotype.

Since PHEX is predominantly expressed in bones (osteoblasts and osteocytes) and teeth (odontoblasts) and not in the kidney, plasma concentrations of a phosphaturic hormone, such as fibroblast growth factor 23 (FGF 23), which is elevated in most affected individuals, is most likely the cause of phosphaturia. ${ }^{17,18}$

FGF 23 not only inhibits phosphate renal reabsorption but also the activity of 1a-hydroxylase.

Standard treatment of XLH patients includes large doses of oral phosphate and calcitriol. Although this therapy, through long-term clinical use, has proved its efficacy in raising serum phosphate and calcitriol levels and improving the clinical features of rickets and osteomalacia, it is often limited by adverse reactions. Phosphaturia and increased absorption of calcium and phosphate can lead to nephrorcalcinosis, while high oral doses of phosphorus often decrease the ionized calcium, thus stimulating PTH secretion from the parathyroid glands and leading to secondary and sometimes tertiary hyperparathyroidism..$^{5-8}$

Moreover, recent data demonstrate that both exogenous phosphate loading and administration of vitamin D can increase FGF23 levels, ${ }^{19-22}$ creating a vicious cycle. Therefore, the main limitation of current treatment of XLH is that it mostly corrects serum phosphate by increasing phosphorus absorption from the gastrointestinal tract, while it does not affect the increased renal phosphate leakage that predominates.

Calcimimetics are compounds that modulate allosterically the calcium sensing receptor $\mathrm{CaR}$ in parathyroid cells,${ }^{19}$ enhancing its sensitivity to circulating serum calcium concentrations and thereby decreasing PTH secretion. Cinacalcet has been approved for the treatment of secondary hyperparathyroidism in end-stage renal disease and recently for the treatment of primary hyperparathyroidism due to parathyroid adenoma, carcinoma or hyperplasia.

Preliminary evidence suggests that cinacalcet can reduce $\mathrm{PTH}$ secretion in response to a phosphate load in patients with XLH, thus reducing the possibility of developing secondary hyperparathyroidism, ${ }^{9,10}$ that subsequently leads to arterial hypertension and impaired renal function. It has been demonstrated ${ }^{10}$ that the reduction in $\mathrm{PTH}$, induced by short-term administration of cinacalcet, was associated with an increase in TmP/GFR and serum phosphate that exceeded the values obtained with oral phosphate alone or with the traditional combination of phosphate and calcitriol therapy. Furthermore, Geller et $\mathrm{al}^{24}$ added cinacalcet to the standard therapy in two patients with tumor-induced osteomalacia, allowing the use of lower doses of both phosphate and calcitriol.

In our case, addition of cinacalcet reduced PTH and calcium levels and increased serum phosphate, as was expected. In addition, we also noticed a significant decrease in FGF23 levels, which remained stable after six months of therapy (Table 1).

In conclusion, long-term studies are needed to investigate further whether the addition of calcimimetics to the treatment protocol of XLH patients will be of value. It is clear, however, that future treatment of XLH should include the direct targeting of FGF23 levels and cinacalcet seems to represent a new and promising agent in this respect.

\section{REFERENCES}

1. Quarles LD, 2003 Evidence for a bone-kidney axis regulating phosphate homeostasis. J Clin Invest 112: 642-646.

2. Jonsson KB, Zahradnik R, Larsson T, et al, 2003 Fi- 
broblast growth factor 23 in oncogenic osteomalacia and X-linked hypophosphatemia. N Eng J of Med 348: 1656-1663.

3. Baroncelli GI, Bertelloni S, Sodini F, et al, 2004 Genetic advances, biochemical and clinical features and critical approach to treatment of patients with X-linked hypophosphatemic rickets. Pediatr Endocrinol Rev 1: 361-379.

4. Cho HY, Lee BH, Kang JH, Ha IS, Cheong HI, Choi Y, 2005 A clinical and molecular genetic study of hypophosphatemic rickets in children. Pediatr Res 58: 329-333.

5. Verge CF, Lam A, Simpson JM, Cowell CT, Howard NJ, Silink M, 1991 Effects of therapy in X-linked hypophosphatemic rickets. N Eng J of Med 325: 18431848.

6. Schmitt CP, Mehls O, 2004 The enigma of hyperparathyroidism in hypophosphatemic rickets. Pediatr Nephrol 19: 473-477.

7. Alon US, Monzavi R, Lilien M, Rasoulpour M, Geffner ME, Yadin O, 2003 Hypertension in hypophosphatemic rickets - role of secondary hyperparathyroidism. Pediatr Nephrol 18: 155-158.

8. Nehgme R, Fahey JT, Smith C, Carpenter TO, 1997 Cardiovascular abnormalities in patients with $\mathrm{X}$-linked hypophosphatemia. J Clin Endocrinol Metab 82: 24502454.

9. Raeder H, Shaw N, Netelenbos C, Bjerknes R, 2008 A case of X-linked hypophosphatemic rickets: complications and the therapeutic use of cinacalcet. Eur $\mathbf{J}$ Endocrinol 159: Suppl 1: 101-105.

10. Alon US, Levy-Olomucki R, Moore WV, Stubbs J, Liu S, Quarles LD, 2008 Calcimimetics as an adjuvant treatment for familial hypophosphatemic rickets. Clin J Am Soc Nephrol 3: 658-664.

11. Brame LA, White KE, Econs MJ, 2004 Renal phosphate wasting disorders: clinical features and pathogenesis. Semin Nephrol 24: 39-47.

12. The HYP Consortium, 1995 A gene (PEX) with homologies to endopeptidases is mutated in patients with $\mathrm{X}$-linked hypophosphatemic rickets. Nat Genet 11: 130-136.

13. Rowe PS, Oudet C, Francis F, et al, 1997 Distribution of mutations in the PEX gene in families with X-linked hypophosphataemic rickets (HYP). Hum Mol Genet 6: 539-549.

14. Dixon PH, Christie PT, Wooding C, et al, 1998 Mutational analysis of the PHEX gene in X-linked hypophosphataemia. 1998. J Clin Endocrinol Metab 83: 3615-3623.

15. Francis F, Strom TM, Hennig S, et al, 1997 Genomic organization of the human PEX gene mutated in Xlinked dominant hypophosphatemic rickets. Genome Res 7: 573-585.

16. Popowska E, Pronicka E, Sulek A, et al, 2001 X-linked hypophosphatemia in Polish patients. 2. Analysis of clinical features and genotype-phenotype correlation. Journal of Applied Genetics 42:73-88.

17. Jonsson KB, Zahradnik R, Larsson T, et al, 2003 Fibroblast growth factor 23 in oncogenic osteomalacia and X-linked hypophosphatemia. N Engl J Med 348: 1656-1663.

18. Yamazaki Y, Okazaki R, Shibata M, et al, 2002 Increased circulatory level of biologically active full-length FGF-23 in patients with hypophosphatemic rickets/osteomalacia. J Clin Endocrinol Metab 87: 4957-4960.

19. Perwad F, Azam N, Zhang MY, Yamashita T, Tenenhouse HS, Portale AA, 2005 Dietary and serum phosphorus regulate fibroblast growth factor 23 expression and 1,25-dihydroxyvitamin D metabolism in mice. Endocrinology 146: 5358-5364.

20. Burnett SM, Gunawardene SC, Bringhurst FB, Juppner H, Lee H, Finkelstein FS, 2006 Regulation of C-terminal and intact FGF23 by dietary phosphate in men and women. J Bone Miner Res 21: 1187-1196.

21. Collins MT, Lindsay JR, Jain A, et al, 2005 Fibroblast growth factor-23 is regulated by 1,25-dihydroxyvitamin D. J Bone Miner Res 20: 1944-1950.

22. Liu S, Tang W, Zhou J, et al, 2006 Fibroblast growth factor 23 is a counter-regulatory phosphaturic hormone for vitamin D. J Am Soc Nephrol 17: 1305-1315.

23. Nemeth EF, Steffey ME, Hammerland LG, 1998 Calcimimetics with potent and selective activity on the parathyroid calcium receptor. Proc Natl Acad Sci USA 95: 4040-4045.

24. Geller JL, Khosravi A, Kelly MH, Riminucci M, Adams JS, Collins MT, 2007 Clinacalcet in the management of tumor-induced osteomalacia. J Bone Miner Res 22: 931-937. 